\title{
Assaying the effect of yeasts on growth of fungi associated with disease
}

\author{
Enikő Horváth, Matthias Sipiczki, Hajnalka Csoma and Ida Miklós
}

\begin{abstract}
Background: Pathogenic fungi often cause serious infections mainly in immunocompromised persons. The number of infections caused by the non-albicans Candida or other species has significantly increased over the last years. These infections present a major challenge in the health sector because these pathogenic fungi have strong virulence and often show resistance to the commonly used antifungal treatments. To solve the problems caused by the drug resistant pathogenic fungi, it is necessary to find new antifungal agents and their sources. The aim of this study was to give evidence that yeasts can effectively fight against strains which belong to pathogenic fungi and reveal those yeasts which are able to inhibit growth of Kodamaea ohmeri, Pichia kudriavzevii, Naganishia albida or Candida tropicalis. Furthermore, we wanted to determine the effects of certain culturing factors on the growth inhibition.

Results: Our screening revealed that although the strains belonging to pathogenic species were much more tolerant to the yeast-produced bioactive agents than the non-disease-associated yeasts, growth of Kodamaea ohmeri and Candida tropicalis could be inhibited by Metschnikowia andauensis, while Naganishia albida could be controlled by Pichia anomala or Candida tropicalis. Our data proved that the experimental circumstances could have a serious impact on the inhibitory capacity of the yeasts. Appearance of inhibition strongly depended on media, $\mathrm{pH}$ and temperature. Our data also shed some light on the fact that Pichia kudriavzevii must have high natural resistance to the yeast-produced agents, while other species, such as Saccharomycopsis crataegensis belonged to the easily inhibitable species.

Conclusions: Our study suggests that yeast-produced bioactive agents could be potential growth inhibitory agents against the disease-associated fungi and yeasts can also contribute to alternative approaches to combat against pathogenic fungi. Our data revealed an important role of the culturing factors in inhibition and pointed to the complex nature of antagonism.
\end{abstract}

Keywords: Disease-associated fungi, Bioactive agents, Yeast, Antagonism, Metschnikowia sp., Non-albicans Candida species, Natural resistance

\section{Background}

Fungaemia is associated with substantial morbidity and mortality of immunocompromised persons. Studies have demonstrated that fungal sepsis can quite often be caused by non-albicans Candida or other species, such as Candida tropicalis, Pichia kudriavzevii (synonyme Candida krusei), Kodamaea ohmeri (synonyme Candida guillermondii) cells or Naganishia albida (formerly Cryptococcus albidus) ([1, 2], reviewed in [3-9]).

\footnotetext{
* Correspondence: miklos.ida@science.unideb.hu

Department of Genetics and Applied Microbiology, Faculty of Science and

Technology, University of Debrecen, Debrecen, Egyetem tér 1 4032, Hungary
}

However, the most frequent species which can cause candidemia can depend on regions, age of the patients, or type of the medical interventions (reviewed in [10]). According to the reports, Pichia kudriavzevi cells were isolated from hematology-oncology services or neonatal care units in different geographic locations and it was supposed to be the fifth most common cause of candidemia $[1,2]$. Kodamaea ohmeri cells were isolated from infant and neonate, from wound lesions and blood [reviewed in 3, 4, 5, 6]. Candida tropicalis is one of the most common colonizer in tropical countries [reviewed in 11]. Its infections can be found both in animals and

C The Author(s). 2020 Open Access This article is licensed under a Creative Commons Attribution 4.0 International License, which permits use, sharing, adaptation, distribution and reproduction in any medium or format, as long as you give appropriate credit to the original author(s) and the source, provide a link to the Creative Commons licence, and indicate if changes were made. The images or other third party material in this article are included in the article's Creative Commons licence, unless indicated otherwise in a credit line to the material. If material is not included in the article's Creative Commons licence and your intended use is not permitted by statutory regulation or exceeds the permitted use, you will need to obtain permission directly from the copyright holder. To view a copy of this licence, visit http://creativecommons.org/licenses/by/4.0/ The Creative Commons Public Domain Dedication waiver (http://creativecommons.org/publicdomain/zero/1.0/) applies to the data made available in this article, unless otherwise stated in a credit line to the data. 
humans and can cause gastrointestinal invasions or arthritis ([11], reviewed in [7, 12]). Naganishia albida was isolated from transplant recipients or lesions ([8], reviewed in [9]).

The major therapeutic challenges of the health sector arise from the resistance of these pathogenic fungi to the commonly used antifungal agents that greatly contribute to their survival and successful infections ( $[5,11]$, reviewed in $[7,13])$. Consequently, finding new inhibitory agents against these disease-associated fungi is becoming increasingly urgent.

Different studies have tried to find bioactive agents which can inhibit cell division or hyphal formation of these pathogenic fungi [14-16]. Mostly they wanted to find effective agents by screening new synthetic drugs or testing natural agents, such as antimycotic plant oils [1416]. To solve the fungal resistance problem, a further possibility can be investigation and application of the yeasts having biocontrol capacity or the yeast-produced antifungal agents. Namely, yeast species are often able to reduce or inhibit growth of destructive microbes ([17, 18] reviewed in $[19,20])$. Different mechanisms, such as competition for nutrients, or secretion of antifungal compounds have been proposed as being responsible for their antagonistic activity ([21], reviewed in $[19,20,22])$. They can produce siderophores, cell wall degrading enzymes or further unknown bioactive agents [23-29].

Based on the above, we hypothesized that yeasts can effectively fight also against disease-associated fungi. That is, in this study we wanted to find out whether cell division of the strains belonging to non-albicans Candida disease-associated fungi, such as Candida tropicalis, Pichia kudriavzevii, Kodamaea ohmeri or Naganishia albida could be inhibited by certain yeast species or not.

A further aim of ours was to find these inhibitory yeast species and influencing factors of the inhibition. To this end, type strains, strains isolated from nature, strains belonging to well-known antagonistic species and species not studied for biological control were equally tested.

Our screening provided further evidence for the antagonistic ability of yeasts, revealed those species which were able to inhibit cell division of the strains which belong to infectious fungi. The data proved that the appearance of inhibition can strongly depended on the media, $\mathrm{pH}$ and temperature. Our data also suggested that Pichia kudriavzevii must have strong inherited resistance to the yeast-produced antifungal agents.

\section{Results}

Growth of Kodamaea ohmeri, Candida tropicalis and Naganishia albida cells could be inhibited by yeast species

In order to find yeast species which are able to inhibit cell division of the strains belonging to disease-associated species, several yeasts (test-strains) were investigated. Species with known and un-known biocontrol capacity were equally tested (Table 1). Our results showed that growth of Kodamaea ohmeri (Fig. 1a) and Candida tropicalis could be inhibited by $M$. andauensis cells, while Naganishia albida was controlled by $P$. anomala and C. tropicalis (Table 1)(indicated with +). Other test-species, among them the well-known antagonistic species, such as Metschnikowia pulcherrima were not able to form an inhibitory zone on the lawn of the strains of diseaseassociated species (indicated with -), in turn they were effective in the case of several strains belonging to nondisease-associated species (Table 1). The Saccharomycopsis crataegensis and Wickerhamomyces orientalis species were especially sensitive. They were inhibitable by almost all the test-strains, while the Pichia kudriavzevii seemed to be rather resistant (Table 1). Interestingly, in some cases, growth stimulation of the lawn (indicated with $\mathrm{S}$ in the Table 1, Fig. 1b) or co-occurrence of inhibitory- and stimulation zones could also be detected (indicated with I-S in the Table 1, Fig. 1c).

\section{Pichia kudriavzevii has strong resistance}

Our previous screening suggested that Pichia kudriavzevii could have strong resistance to the yeast-produced agents (Table 1). To learn whether this is true or not, further test-strains belonging to different species and originating from different regions of the world were investigated on the Pichia kudriavzevii lawn. Our data confirmed the strong resistance of Pichia kudriavzevii (Table 2), since a total of 50 strains belonging to 35 species were not able to inhibit its growth both on complete and minimal media (Table 2). In contrast, Saccharomycopsis crataegensis cells (used as control) could be inhibited by several yeast species (Table 2).

\section{Influencing factors of the growth inhibition}

Our earlier observation (Table 2-Saccharomycopsis crataegensis) and previous studies [30, 31] have suggested that medium and culture conditions can have a strong impact on biocontrol activity. Thus, we repeated our experiments with one of the disease-associated species (Naganishia albida) applying minimal (EMMA) and complete (YPA) media, different $\mathrm{pH}$, temperature and using further test-strains. Our data confirmed that culture conditions can strongly influence antagonistic effect of the test-strains and optimal conditions of antagonism can be species-specific (Table 3). Changes of the $\mathrm{pH}$ value or medium influenced the growth inhibition differently in the case of the different species (Fig. 2, Table 3). There was a less sensitive strain (Candida insectorum), a strain which showed inhibitory capacity only at lower $\mathrm{pH}$, such as Pichia dorogensis, while the appearance of antagonism depended on the media in the case of 
Horváth et al. BMC Microbiology

(2020) 20:320

Page 3 of 10

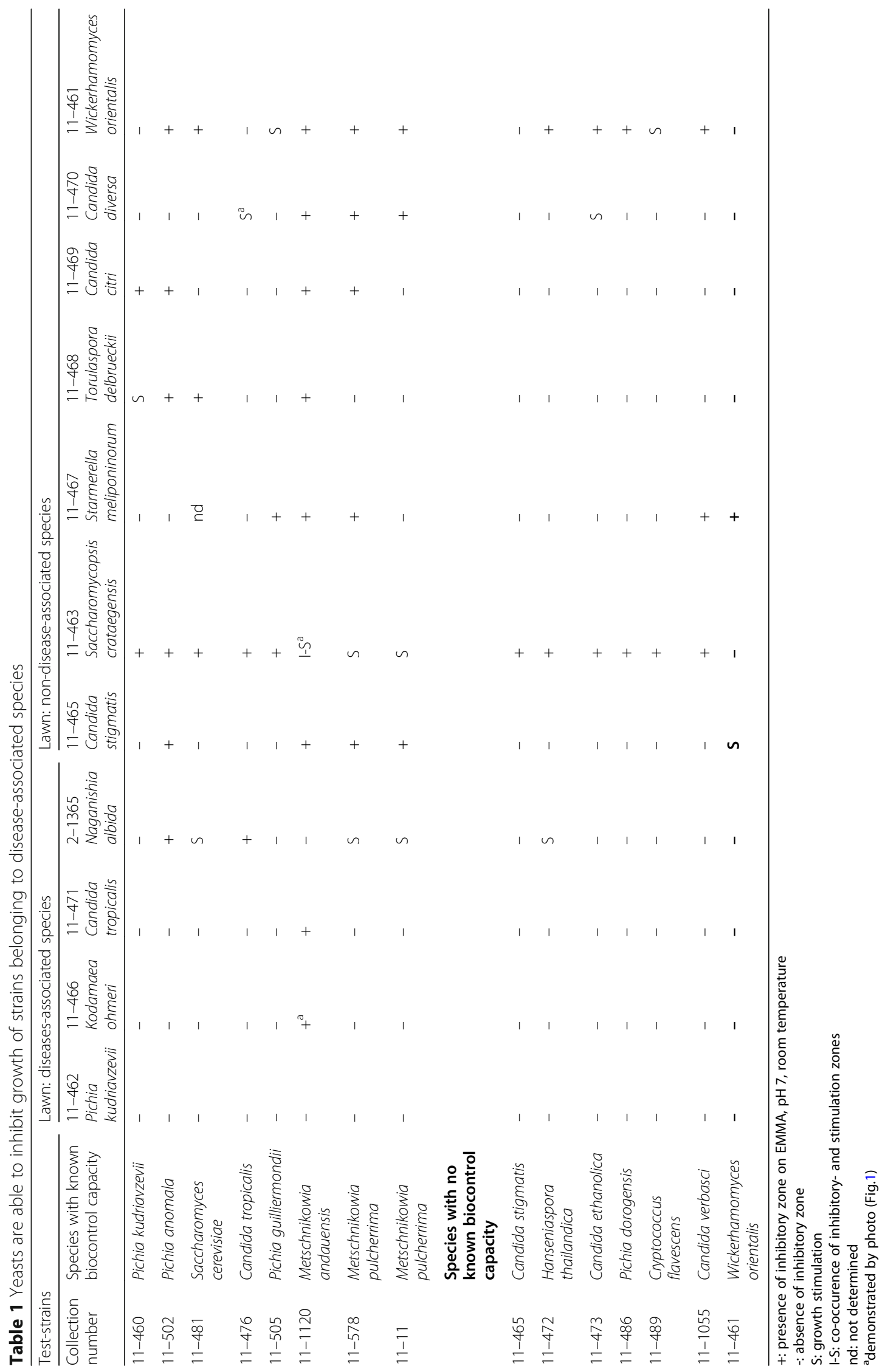




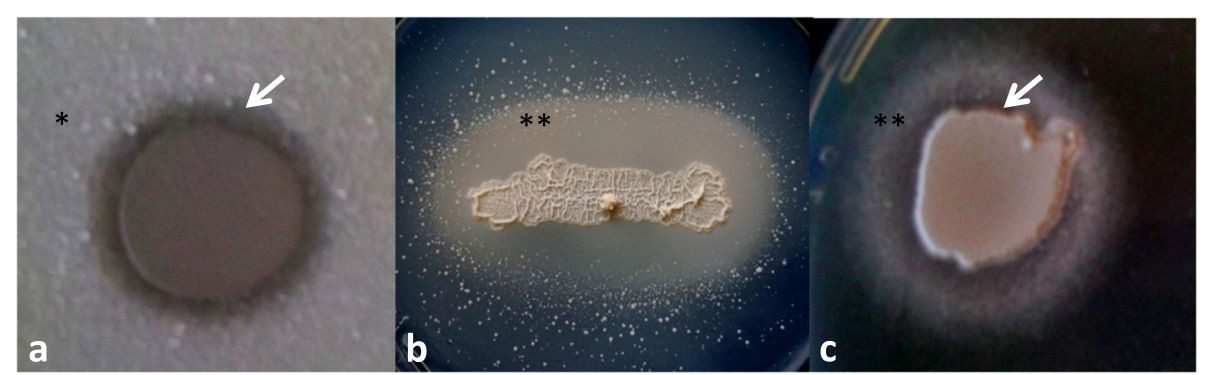

Fig. 1 Yeast-produced bioactive agents can cause not only inhibition, but growth stimulation. a Inhibition - lawn: Kodamae ohmeri (11-466), teststrain: Metschnikowia andauensis (11-1120) (C. tropicalis lawn gave similar result). (White arrows show the clear inhibitory zone, where cells of the lawn could not divide. * indicates the growing cells of the lawn farther from the test-strain). b Growth stimulation - lawn: Candida diversa (11470), test-strain: Candida tropicalis (11-476). ** indicates the growth stimulation. c Co-occurence of inhibitory- and stimulation zones-lawn: Saccharomycopsis crataegensis (11-463), test-strain: Metschnikowia andauensis (11-1120). EMMA media (pH 6.5) were incubated at room temperature and photographed after 5 days

Trichosporon asahii or Sporidiobolus ruineniae (Table 3). Inhibitory capacity of Wickerhamomyces orientalis seemed to be influenced by temperature (Table 3). Modification of the culture factors could lead to finding further antagonistic species against Naganishia albida (e.g. Candida insectorum or Pichia dorogensis)(Table 3).

\section{Discussion}

Non-albicans Candida or other species, such as Naganishia albida are frequently isolated from hospitalized persons [1-13]. A major issue in the health sector is that these species often show resistance to the commonly used antifungal treatments $[2,5,7,13]$. The consequences of these fungal infections can be very serious, especially in children, neonates or immunocompromised patients. Thus, finding new inhibitory agents and their possible sources is becoming increasingly urgent.

Earlier studies have observed that antagonistic interaction can occur between yeasts species and they can regulate each other's growth [17, 19-24, 32]. Antagonistic yeasts have mainly been investigated against postharvest pathogens of fruits and vegetables [17, 19-24, 32] and only a small number of data suggest that yeasts could also inhibit fungi associated with disease [18]. Based on the above, the main focus of this study was to reveal those yeasts which were able to inhibit growth of strains which belong to pathogenic species. Type strains, strains isolated from nature, species with known and unknown antagonistic capacity were equally tested against the medically important fungi. Our data revealed that growth of Kodamaea ohmeri and Candida tropicalis could be inhibited by Metschnikowia andauensis, while Naganishia albida could be controlled by Pichia anomala and Candida tropicalis. These results are in good agreement with the experimental data of Kunyeit, who has demonstrated an inhibitory effect of the probiotic yeasts [18]. Our data also confirm that yeasts can be promising means of the fight against pathogenic fungi, can influence future trends of antimicrobial treatment and they can be sources of new antifungal agents.

However, we have to notice that the strains belonging to pathogenic fungi were somehow much more tolerant to the yeast-produced bioactive agents than the nondisease-associated yeasts, such as e.g. Saccharomycopsis crataegensis and Wickerhamomyces orientalis. One of them, Pichia kudriavzevii was especially tolerant to yeast-produced bioactive agents, because we failed to find any inhibitory yeast against it after application of 50 different test-strains (belonging to 35 species). Causes of its high resistance are not known and require further study. We suppose that it can be an inherited natural species-specific feature of Pichia kudriavzevii, because our strain was isolated from nature and had not previously come into contact with antifungal medicaments. Its high natural tolerance might be related to the multidrug resistance found in the clinical isolates [2].

Antagonism can be attributed to different features, such as competition for nutrients, or secretion of antifungal compounds ([21], reviewed in [19, 20, 22]). However, enzymes and proteins produced by antagonistic yeasts are partly known [33-37], we do not know exactly which inhibitory agents of our yeasts investigated were effective against the strains belonging to the diseaseassociated species. Further studies are required to identify these yeast-produced drugs. We assume that majority of the inhibitory test-strains might produce different bioactive agents because their antagonistic capacity was mostly influenced by different experimental factors. In certain cases the complete medium, while in other cases the lower $\mathrm{pH}$ favored the appearance of inhibition. These results drew our attention that optimal conditions of antagonism can be species-specific and its appearance strongly depends on the partner microbes. These results might be supported by data obtained with antagonistic yeasts used in postharvest disease control of fruits [30, 31]. Studying of the culture factors was useful because it 
Table 2 Pichia kudriavzevii has strong resistance against yeast-produced bioactive agents

\begin{tabular}{|c|c|c|c|c|c|}
\hline \multicolumn{4}{|l|}{ Test-strains } & \multicolumn{2}{|l|}{ Inhibitory zone } \\
\hline \multirow[t]{3}{*}{ Collection number } & Species & Origin & Isolation source & $\begin{array}{l}11-460^{\mathrm{a}} \\
\text { Pichia kudriavzevii }\end{array}$ & $\begin{array}{l}11-463^{\mathrm{a}} \\
\text { Saccharomycopsis crataegensis }\end{array}$ \\
\hline & & & & Media & \\
\hline & & & & EMMA/YPGA & EMMA/YPGA \\
\hline $11-502$ & Pichia anomala & Laos, Luang Prabang & flower & $-/-$ & $-/+$ \\
\hline $11-520$ & Pichia anomala & Laos, Vientiane & plant-louse & $-/-$ & $-/+$ \\
\hline $11-522$ & Pichia anomala & Laos, Vientiane & flower & $-/-$ & $-/+$ \\
\hline $11-485$ & Pichia bruneiensis & Borneo, Brunei & flower & $-1-$ & $-/+$ \\
\hline $11-480$ & Pichia manshurica & Philippines, Manila & banana & $-/-$ & $+/-$ \\
\hline $11-461$ & Wickerhamomyces orientalis & Sri Lanka, Galle & fruit & $-/-$ & $-/-$ \\
\hline $11-496$ & Saccharomycopsis crataegensis & Philippines, Manila & rotting fruit & $-1-$ & $-1-$ \\
\hline $11-464$ & Metschnikowia koreensis & India, Hyderabad & flower & $-1-$ & $-/-$ \\
\hline $11-482$ & Metschnikowia koreensis & Borneo, Brunei & flower & $-/-$ & $-/+$ \\
\hline $11-524$ & Metschnikowia laotica & Laos, Luang Prabang & fruit & $-/-$ & $-/+$ \\
\hline $11-1062$ & Metschnikowia pulcherrima & Georgia, Tbilisi & fruit & $-/-$ & $-/+$ \\
\hline $11-523$ & Candida glabrata & Laos, Vientiane & flower & $-/-$ & $+/-$ \\
\hline $11-484$ & Candida boidinii & Borneo, Brunei & flower & $-/-$ & $-/-$ \\
\hline $11-471$ & Candida tropicalis & Philippines, Caticlan & banana & $-/-$ & $-/-$ \\
\hline $11-521$ & Candida tropicalis & Laos, Vientiane & mushroom & $-/-$ & $-/+$ \\
\hline $11-470$ & Candida diversa & Borneo, Brunei & mango & $-1-$ & $+/-$ \\
\hline $11-477$ & Candida californica & Borneo, Brunei & fruit & $-/-$ & $-/-$ \\
\hline $11-478$ & Candida californica & Borneo, Brunei & fruit & $-/-$ & $-/-$ \\
\hline $11-473$ & Candida ethanolica & Borneo, Brunei & papaya & $-1-$ & $-1-$ \\
\hline $11-469$ & Candida citri & Borneo, Brunei & lemon & $-/-$ & $-/+$ \\
\hline $11-488$ & Candida pseudointermedia & Borneo, Brunei & flower & $-1-$ & $-1+$ \\
\hline $11-479$ & Candida zemplinina & Philippines, Manila & banana & $-/-$ & $-/-$ \\
\hline $11-487$ & Candida borneonana & Borneo, Brunei & rotting fruit & $-/-$ & $-/-$ \\
\hline $11-504$ & Candida intermedia & Laos, Luang Prabang & flower & $-/-$ & $-/+$ \\
\hline $11-506$ & Candida jaroonii & Laos, Luang Prabang & rotting fruit & $-/-$ & $-/+$ \\
\hline $11-512$ & Candida jaroonii & Laos, Luang Prabang & flower & $-/-$ & $-/+$ \\
\hline $11-514$ & Candida jaroonii & Laos, Luang Prabang & flower & $-/-$ & $-/+$ \\
\hline $11-507$ & Candida suratensis & Laos, Luang Prabang & rotting fruit & $-/-$ & $-/+$ \\
\hline $11-509$ & Candida suratensis & Laos, Luang Prabang & fruit & $-/-$ & $-/+$ \\
\hline $11-510$ & Candida suratensis & Laos, Luang Prabang & fruit & $-/-$ & $-/+$ \\
\hline $11-513$ & Candida butyri & Laos, Luang Prabang & flower & $-/-$ & - \\
\hline $11-517$ & Candida sergipensis & Laos, Vientiane & leaf & $-/-$ & $+/-$ \\
\hline $11-519$ & Candida parapsilosis & Laos, Vientiane & plant-louse & $-/-$ & $-/-$ \\
\hline $11-466$ & Kodamaea ohmeri & India, Hyderabad & flower & $-1-$ & $-/+$ \\
\hline $11-490$ & Kodamaea ohmeri & Philippines, Manila & fruit & $-/-$ & $-/+$ \\
\hline $11-500$ & Kodamaea ohmeri & Philippines, Manila & fruit & $-/-$ & $-/+$ \\
\hline $11-467$ & Starmerella meliponinorum & India Hyderabad & flower & $-/-$ & $+/-$ \\
\hline $11-1071$ & Starmerella caucasica & Azerbaijan, Baku & flower & $-/-$ & $+/-$ \\
\hline $11-474$ & Torulaspora delbrueckii & Borneo, Brunei & papaya & $-/-$ & $+/-$ \\
\hline $11-475$ & Issatchenkia terricola & Borneo, Brunei & lemon & $-/-$ & $-/-$ \\
\hline
\end{tabular}


Table 2 Pichia kudriavzevii has strong resistance against yeast-produced bioactive agents (Continued)

\begin{tabular}{|c|c|c|c|c|c|}
\hline Test-strains & & & & Inhib & \\
\hline $11-491$ & Hanseniaspora thailandica & Philippines, Manila & rotting fruit & $-1-$ & $-1-$ \\
\hline $11-495$ & Hanseniaspora thailandica & Philippines, Manila & rotting fruit & $-1-$ & $-/-$ \\
\hline $11-499$ & Hanseniaspora thailandica & Philippines, Manila & rotting fruit & $-1-$ & $-/-$ \\
\hline $11-494$ & Hanseniaspora uvarum & Philippines, Manila & papaya & $-/-$ & $-/-$ \\
\hline $11-501$ & Aureobasidium pullulans & Philippines, Manila & fruit & $-/-$ & $-/+$ \\
\hline $11-511$ & Metahyphopichia laotica & Laos, Luang Prabang & fruit & $-1-$ & $-/-$ \\
\hline $11-516$ & Metahyphopichia laotica & Laos, Vientiane & flower & $-1-$ & $-/+$ \\
\hline $11-518$ & Cryptococcus heveanensis & Laos, Vientiane & flower & $-1-$ & $-1-$ \\
\hline $11-489$ & Cryptococcus flavescens & Philippines, Banaue & fruit & $-1-$ & $+/-$ \\
\hline
\end{tabular}

Petri dishes were incubated at room temperature

+ : presence of inhibitory zone

-: absence inhibitory zone

${ }^{a} 11-460$ and $11-463$ species used as lawn were isolated from Sri Lanka, Colombo

could lead to finding further inhibitory strains against Naganishia albida and suggested that antagonistic tests are worth to carry out under different circumstances. Our data also shed some light on the complexity of the interaction between yeasts, because, besides inhibition, growth stimulation or co-appearance of inhibitory- and stimulation zones were also noticed, similarly to other species [38].

Taken together, this study provides further evidence that certain yeast species can be good candidates for finding those new bioactive agents that can be suitable to inhibit cell division of the disease-associated fungi. The results also drew our attention to the important role of culture conditions in antagonism.

\section{Conclusions}

The significance of this study is that it has revealed those yeast species which are able to inhibit growth of Naganishia albida, Kodamaea ohmeri, Candida tropicalis strains, whose number is increasing in the isolates originating from hospitalized persons. Our data give evidence that certain yeast species might be good basics of new alternative approaches to combat fungal infections. Since our data pointed to the important role of certain culture factors on inhibition, the complex nature of yeast-yeast interaction and high natural resistance of the Pichia kudriavzevii, they can contribute to the precise development of experimental conditions of future studies.

\section{Methods}

\section{Origin of the strains and yeast isolation}

Strains used in this study were collected by Prof. Sipiczki from different regions of the world, except for three type-strains, Metschnikowia andauensis (11-1120, HA 1657) and Metschnikowia pulcherrima (11-11, CBS 610, ATCC 22032) (11-578, CBS 5833, ATCC 18406) which were purchased from collections. The collected samples originated from fruits or flowers (Table 2), because we wanted to investigate such strains which had not previously come into contact with antifungal medicaments. The fruits and flowers were dissected and samples were taken under aseptic conditions. The samples were put in sterile water and aliquots were spread onto YPA medium. The agar plates were incubated at $25^{\circ} \mathrm{C}$ for 7 days. Single yeast colonies were isolated under sterile circumstances. Phase-contrast microscopy (Olympus BX40) was used to check cell morphology. The isolated strains were stored at $-80^{\circ} \mathrm{C}$ until taxonomic and further tests.

\section{Determination of taxonomic position of the strains}

Taxonomic positions of the collected yeast strains were identified by PCR and sequencing methods. D1/D2 domains of $26 \mathrm{~S}$ rDNA genes were amplified with primers NL1 (5' -GCA TAT CAA TAA GCG GAG GAA AAG$\left.3^{\prime}\right)$ and NL4 (5'-GGTCCG TGT TTC AAG ACG G-3') [39]. PCR parameters were: $94{ }^{\circ} \mathrm{C} 2 \mathrm{~min}, 95^{\circ} \mathrm{C} 1 \mathrm{~min}$, $51^{\circ} \mathrm{C} 1 \mathrm{~min}, 72{ }^{\circ} \mathrm{C} 1 \mathrm{~min},(30 \mathrm{X}) 72^{\circ} \mathrm{C} 10 \mathrm{~min}$. The PCR products were purified and sequenced using the same primers. NCBI database (https://blast.ncbi.nlm.nih.gov/ Blast) was used for the sequence analyses. The taxonomic positions of the strains were accepted when 100\% identity was found to the corresponding sequences of the type-strains deposited in the databases (Fig. S1). Since the strains listed in Tables $1,2,3$ belonged to known species their sequences were not deposited in a database.

\section{Culture media and standard yeast culture conditions}

Generally, yeasts were cultured on Yeast Extract Agar (YEA) medium (1\% yeast extract-VWR J850, 2\% glucose-Fluca 49,159, 2\% agar-Sigma 0540) and incubated at $25^{\circ} \mathrm{C}$. 
Table 3 Influencing factors of the growth inhibition. Alteration of media, $\mathrm{pH}$ and temperature allowed us to identify further antagonistic species against Naganishia albida

\begin{tabular}{|c|c|c|c|c|c|c|c|c|c|}
\hline \multicolumn{2}{|l|}{ Test-strains } & \multicolumn{8}{|c|}{ Lawn: 2-1365 Naganishia albida } \\
\hline $\begin{array}{l}\text { Collection } \\
\text { number }\end{array}$ & Species & $\begin{array}{l}\mathrm{pH}=5 \\
\mathrm{YPGA} 24^{\circ} \mathrm{C}\end{array}$ & $\begin{array}{l}\mathrm{pH}=6.5 \\
\mathrm{YPGA} 24^{\circ} \mathrm{C}\end{array}$ & $\begin{array}{l}\mathrm{pH}=5 \\
\text { EMMA } 24^{\circ} \mathrm{C}\end{array}$ & $\begin{array}{l}\mathrm{pH}=6.5 \\
\text { EMMA } 24^{\circ} \mathrm{C}\end{array}$ & $\begin{array}{l}\mathrm{pH}=5 \\
\mathrm{YPGA} 30^{\circ} \mathrm{C}\end{array}$ & $\begin{array}{l}\mathrm{pH}=6.5 \\
\mathrm{YPGA} 30^{\circ} \mathrm{C}\end{array}$ & $\begin{array}{l}\mathrm{pH}=5 \\
\text { EMMA } 30^{\circ} \mathrm{C}\end{array}$ & $\begin{array}{l}\mathrm{pH}=6.5 \\
\text { EMMA } 30^{\circ} \mathrm{C}\end{array}$ \\
\hline $11-460$ & Pichia kudriavzevii & - & - & - & - & - & - & + & - \\
\hline $11-1146$ & Pichia kudriavzevii & - & - & - & - & - & - & + & - \\
\hline $11-502$ & Pichia anomala & + & + & $-{ }^{a}$ & $t^{a}$ & + & + & - & + \\
\hline $11-481$ & $\begin{array}{l}\text { Saccharomyces } \\
\text { cerevisiae }\end{array}$ & - & - & - & S & - & - & + & - \\
\hline $11-476$ & Candida tropicalis & + & + & - & + & + & + & - & + \\
\hline $11-505$ & $\begin{array}{l}\text { Pichia } \\
\text { guilliermondi }\end{array}$ & - & - & - & - & - & - & - & - \\
\hline $11-1120$ & $\begin{array}{l}\text { Metschnikowia } \\
\text { andauensis }\end{array}$ & - & - & I-S & - & + & - & + & - \\
\hline $11-578$ & $\begin{array}{l}\text { Metschnikowia } \\
\text { pulcherrima }\end{array}$ & - & - & S & - & - & - & S & - \\
\hline $11-11$ & $\begin{array}{l}\text { Metschnikowia } \\
\text { pulcherrima }\end{array}$ & - & - & S & S & & - & S & - \\
\hline $11-465$ & Candida stigmatis & - & - & - & - & - & - & - & - \\
\hline $11-472$ & $\begin{array}{l}\text { Hanseniaspora } \\
\text { thailandica }\end{array}$ & - & - & - & S & - & - & - & - \\
\hline $11-473$ & $\begin{array}{l}\text { Candida } \\
\text { ethanolica }\end{array}$ & - & - & - & - & - & - & - & - \\
\hline $11-486$ & Pichia dorogensis & + & - & + & - & + & - & + & - \\
\hline $11-489$ & $\begin{array}{l}\text { Cryptococcus } \\
\text { flavescens }\end{array}$ & - & - & - & - & - & - & - & - \\
\hline $11-1055$ & Candida verbasci & - & - & - & - & - & - & - & - \\
\hline $11-461$ & $\begin{array}{l}\text { Wickerhamomyces } \\
\text { orientalis }\end{array}$ & + & + & - & - & - & - & - & - \\
\hline $11-523$ & Candida glabrata & - & - & - & - & - & - & - & - \\
\hline $11-1127$ & $\begin{array}{l}\text { Trichosporon } \\
\text { asahii }\end{array}$ & - & - & $+^{a}$ & $+^{a}$ & - & - & + & + \\
\hline $11-1135$ & Pichia kluyveri & - & - & - & - & - & - & - & - \\
\hline $11-1185$ & $\begin{array}{l}\text { Sporidiobolus } \\
\text { ruineniae }\end{array}$ & + & + & - & - & + & + & - & S \\
\hline 11-1193 & $\begin{array}{l}\text { Candida } \\
\text { insectorum }\end{array}$ & + & + & + & + & + & + & + & + \\
\hline $2-1366$ & Candida magnifica & - & - & - & - & - & - & - & - \\
\hline
\end{tabular}

+ : presence of the inhibitory zone

-: absence of the inhibitory zone

nd: not determined,

S: stimulation

I-S: co-occurence of inhibitory- and stimulation zone

${ }^{a}$ : demonstrated by photo (Fig. 2)

For spot assays the inoculum was prepared from cells of a single colony. The cells of the pre- and main cultures were grown in Yeast Peptone Glucose medium (YPG) (1\% yeast extract, $2 \%$ peptone-VWR $84610,2 \%$ glucose) for overnight at $28^{\circ} \mathrm{C}$ in a shaker. Spot assays were carried out on YPGA (YPG + 2.5\% agar) and Edinburgh Minimal Medium (EMMA) [39].

\section{Spot assay to monitor growth inhibition}

The cells of the disease-associated fungi cultured overnight in YPG, at $28^{\circ} \mathrm{C}$, in a shaker, were harvested, washed with sterile distilled water and cell suspension was prepared in sterile water (final cell density was $7 \times$ $10^{7} \mathrm{cell} / \mathrm{ml}$ ). EMMA minimal and YPGA complete media were flooded with $1 \mathrm{~mL}$ of the cell suspension (we called it lawn). When the surface of the plates dried in a 


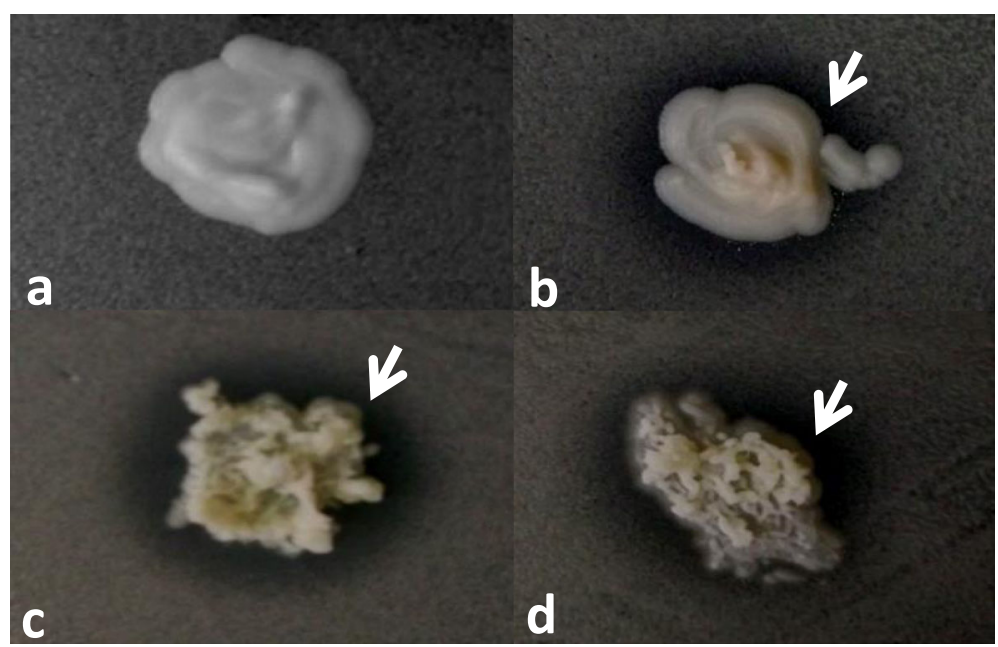

Fig. 2 Effect of pH value on growth inhibition. Growth of Naganishia albida (2-1365) was investigated on EMMA medium (pH 5 and 6.5) in the presence of test-strains Pichia anomala (11-502) and Trichosporon asahii (11-1127). The Petri dishes were incubated at $24^{\circ} \mathrm{C}$ for $3-10$ days. a: Pichia anomala, pH 5, b: Pichia anomala, pH 6.5, c: Trichosporon asahii, pH 5 (d): Trichosporon asahii, pH 6.5. a: absence of inhibitory zone, (b, c, d): presence of inhibitory zone. White arrows show the clear inhibitory zone, where cells of the Naganishia albida (lawn) could not divide

sterile box, the yeast strains to be tested for antagonistic capacity (we called it test-strain) were streaked or dropped (10ul of $7 \times 10^{7}$ cell $/ \mathrm{ml}$ cell suspension) onto the centre of the agar plates (Figs. 1, 2, S2). The Petri dishes were incubated at the indicated temperatures.

Appearance of the clear inhibitory zones (Fig. S2a) was investigated after 3-10 days. When cells of the lawn were not able to grow around the test-strain, while they showed at the same time normal growth without or far from the test-strain -see Fig. 2b,c,d, S2a (and the zone was similar to the inhibitory zones produced by Metschnikowia pulcherrima type strains on the Candida stigmatis lawn), it was indicated with $(+)$ because of the presence of inhibitory zone (see in the Tables). When cells of the lawn were able to grow around the teststrain and showed similar growth as in absence of the test-strain or far from it (see Fig. 2a, Fig. S2b), it was indicated with $(-)$ because of the absence of inhibitory zone (see in the Tables). The lawns were always prepared at the same time, on the same media and were also compared to each other. The results come from three or more separate experiments.

\section{The influencing factors of growth inhibition}

To learn the effect of $\mathrm{pH}$, temperature and composition of the media on the growth inhibition, the spot assays were repeated using EMMA and YPGA media. Their $\mathrm{pH}$ values were set to 5 and 6.5 . We used these two $\mathrm{pH}$ values, because earlier data suggested that antagonistic capacity of several yeast species was similarly at $\mathrm{pH} 5.0$ 5.5 and 6-6.5-7 [35]. The Petri dishes were incubated at
24 and $30^{\circ} \mathrm{C}$ because lower or higher temperatures did not favour the cell division of several species (data not shown). The temperatures of the incubators were checked with thermometer.

\section{Grouping of the strains for growth inhibition assay}

One group of the strains was called "test-strain" and their antimicrobial capacity was investigated. This group contained species with known biocontrol capacity (Pichia anomala, Metschnikowia andauensis, Metschnikowia pulcherrima, Saccharomyces cerevisiae) and species which were randomly selected from those yeasts whose biocontrol capacity was not earlier investigated (Candida stigmatis, Hanseniaspora thailandica, Candida ethanolica, Pichia dorogensis, Cryptococcus flavescens, Candida verbasci, Wickerhamomyces orientalis) (Table 1).

The other group of the species was used as "lawn". The strains belonging to disease-associated species (Pichia kudriavzevii, Kodamaea ohmeri, Candida tropicalis, Naganishia albida) were investigated for growth inhibition (Table 1). Besides the strains which belong to disease-associated species, non-disease related species, such as Saccharomycopsis crataegensis, Starmerella meliponinorum etc. were also tested to reveal whether there is any difference in their sensitivity compared to the yeasts associated with disease. The non-diseaseassociated yeast strains were used as lawn, because our preliminary data suggested that they might be more sensitive than the strains belonging to disease-associated species. 


\section{Supplementary information}

Supplementary information accompanies this paper at https://doi.org/10. 1186/s12866-020-01942-0.

Additional file 1 Figure S1. BLAST analysis of the nucleotide sequence obtained from 11-473 strain. 100\% identity was found to the Candida ethanolica ribosomal DNA (https://blast.ncbi.nlm.nih.gov/Blast). Similar results were obtained in the case of the other strains used in this study. Query: nucleotide sequence of 11-473 strain. Sbjct: nucleotide sequence of Candida ethanolica type-strain

Additional file 2 Figure S2. General arrangement of a spot assay to monitor growth inhibition of the test-strains. (a) presence of the inhibitory zone (white arrow shows the clear inhibitory zone, where the cells were not able to grow around the test-strain in contrast to the distal parts of the lawn. (b) absence of the inhibitory zone. The lawns were prepared at the same time on the same media. (A) and (B) indicate the species which were used as test-strains. (C) indicates the species which was used as lawn.

\section{Acknowledgements}

We thank Ilona Lakatos for technical assistance.

\section{Authors' contributions}

EH performed the experiments and participated in study design. MS collected the strains and determined the taxonomic positions of the strains. HCs participated in the spot-assays and data analysis. IM performed the study design, data analysis and writing the manuscript. All authors read and approved the manuscript.

\section{Funding}

This study was supported by the European Union and the European Social Fund through EFOP-3.6.1-16-2016-00022 and FIK 20428-3/2018 projects. EFOP-3.6.1-16-2016-00022 provided funds for purchase of the reagents and paid a scholarship for EH, while FIK 20428-3/2018 project partly contributed to the purchase of chemicals. The funding bodies were not involved in study design, data collection, analysis and writing of the manuscript.

\section{Availability of data and materials}

All data generated or analysed during this study are included in this published article and its supplementary information files.

\section{Ethics approval and consent to participate}

Not applicable.

\section{Consent for publication}

Not applicable.

\section{Competing interests}

The authors declare no conflict of interest.

Received: 22 January 2020 Accepted: 11 August 2020

Published online: 21 October 2020

\section{References}

1. Nagarathnamma T, Chunchanur SK, Rudramurthy SM, Vineetha KR, Ramamurthy K, Joseph J, Ambica R. Outbreak of Pichia kudriavzevii fungaemia in a neonatal intensive care unit. J Med Microbiol. 2017;66(12): 1759-64.

2. Pfaller MA, Diekema DJ, Gibbs DL, Newell VA, Nagy E, Dobiasova S, Rinaldi M, Barton R, Veselov A, Global Antifungal Surveillance Group. Candida krusei, a multidrug-resistant opportunistic fungal pathogen: geographic and temporal trends from the ARTEMIS DISK Antifungal Surveillance Program, 2001 to 2005. J Clin Microbiol. 2008;46(2):515-21.

3. Ayaka T, Nei T, Sugimoto R, Watanabe A, Hagiwara J, Takiguchi T, Yokota $H$, Kamei K. Kodamaea ohmeri fungemia in severe burn: Case study and literature review. Med Mycol Case Rep. 2018;22:21-3.

4. Vivas R, Beltran C, Munera MI, Trujillo M, Restrepo A, Garcés C. Fungemia due to Kodamaea ohmeri in a young infan and review of the literature. Med Mycol Case Rep. 2016;13:5-8.
5. $\quad$ Yang BH, Peng MY, Hou SJ, Sun JR, Lee SY, Lu JJ. Fluconazole-resistant Kodamaea ohmeri fungemia associated with cellulitis: Case report and review of the literature. Int J Infect Dis. 2009;13(6):e493-7.

6. Al-Sweih N, Khan ZU, Ahmad S, Devarajan L, Khan S, Joseph L, Chandy R. Kodamaea ohmeri as an emerging pathogen: a case report and review of the literature. Med Mycol. 2011;49(7):766-70.

7. Kothavade RJ, Kura MM, Valand AG, Panthaki MH. Candida tropicalis: its prevalence, pathogenicity and increasing resistance to fluconazole. J Med Microbiol. 2010;59(8):873-80.

8. Lee YA, Kim HJ, Lee TW, Kim MJ, Lee MH, Lee JH, Ihm CG. First Report of Cryptococcus albidus-induced disseminated Cryptococcosis in a renal transplant recipient. Korean J Intern Med. 2004;19(1):53-7.

9. Gharehbolagh SA, Nasimi M, Afshari AKS, Ghasemi Z, Rezaie S. First case of superficial infection due to Naganishia albida (formerly Cryptococcus albidus) in Iran: A review of the literature. Curr Med Mycol. 2017;3(2):33-7.

10. Vaezi A, Fakhim H, Khodavaisy S, Alizadeh A, Nazeri M, Soleimani A, Boekhout T, Badali H. Epidemiological and mycological characteristics of candidemia in Iran: A systematic review and meta-analysis. J Mycol Med. 2017;27(2):146-52

11. Cordeiro RA, Oliveira JS, Collares DS, Castelo-Branco M, Teixeira CEC, Marques FJF, Bittencourt PV, Carvalho VL, Bandeira TJPG, Brilhante RSN, Moreira JLB, Pereira-Neto WA, Sidrim JJC, Rocha MFG. Candida tropicalis isolates obtained from veterinary sources show resistance to azoles and produce virulence factors. Med Mycol. 2015;53(2):145-52.

12. Zuza-Alves DL, Walicyranison PSR, Chaves GM. An Update on Candida tropicalis Based on Basic and Clinical Approaches. Front Microbiol. 2017; 13(8):1927.

13. Pelletier R, Alarie I, Lagacé R, Walsh TJ. Emergence of disseminated candidiasis caused by Candida krusei during treatment with caspofungin: Case report and review of literature. Med Mycol. 2005;43(6):559-64.

14. Hagit BJ, Gonzalez NV, Ben-Aroya S, Stephen J, Kron SJ, Kornitzer D. Chemical inhibitors of Candida albicans hyphal morphogenesis target endocytosis. Sci Rep. 2017;7(1):5692.

15. Pietrella D, Angiolella L, Vavala E, Rachini A, Mondello F, Ragno R, Bistoni F, Vecchiarelli A. Beneficial effect of Mentha suaveolens essential oil in the treatment of vaginal candidiasis assessed by real-time monitoring of infection. BMC Complement Altern Med. 2011;11(18):5-10.

16. Agarwal V, Lal P, Pruthi V. Prevention of Candida albicans biofilm by plant oils. Mycopathologia. 2008;165(1):13-9.

17. Liu J, Sui Y, Wisniewski M, Droby S, Liu Y. Review: Utilization of antagonistic yeasts to manage postharvest fungal diseases of fruit. Int J Food Microbiol. 2013;95(1):69-75.

18. Kunyeit L, Kurrey NK, Anu-Appaiah KA, Rao RP. Probiotic Yeasts Inhibit Virulence of Non-albicans Candida Species. mBio. 2019;10(5):e02307-19.

19. Wilson $\mathrm{CL}$, Wisniewski ME, Biles CL, McLaughlin R, Chalutz E, Droby S. Biological control of post-harvest diseases of fruits and vegetables: alternatives to synthetic fungicides. Crop Protection. 1991;10:172-7.

20. Heydari A, Pessarakli M. A review on biological control of fungal plant pathogens using microbial antagonists. J Biol Sci. 2010;10:273-90.

21. Zhimo VY, Dilip D, Sten J, Ravat VK, Bhutia DD, Panja B, Saha J. Antagonistic yeasts for biocontrol of the banana postharvest anthracnose pathogen Colletotrichum musae. J Phytopathol. 2017;165:35-43.

22. Chan Z, Tian S. Interaction of antagonistic yeasts against postharvest pathogens of apple fruit and possible mode of action. Postharvest Biol Technol. 2005;36:215-23.

23. Wilson $\mathrm{CL}$, Chalutz E. Postharvest biological control of Penicillium rots of citrus with antagonistic yeasts and bacteria. Sci Hortic. 1989:40:105-12.

24. Ghosh SK, Banerjee S, Sengupta C. Siderophore production by antagonistic fungi. J Biopest. 2017;10(2):105-12.

25. Hashem M, Alamri SA, Hesham AL, FMH A-Q, Kilany M. Biocontrol of apple blue mould by new yeast strains:Cryptococcus albidus KKUY0017 and Wickerhamomyces anomalus KKUY0051 and their mode of action. Biocontrol Sci Technolo. 2014;24(10):1137-52.

26. Guerrero V, Guigon C, Berlanga D, Ojeda D. Complete control of Penicillium expansum on apple fruit using a combination of antagonistic yeast Candida oleophila. Chilean J Agric Res. 2014;74(4):427-31.

27. Reyes MEQ, Rohrbach KG, Paull RE. Microbial antagonists control postharvest black rot of pineapple fruit. Postharvest Biol Technol. 2004:33: 193-203.

28. Mayo S, Gutiérrez S, Malmierca MG, Lorenzana A, Campelo MP, Hermosa R, Casquero PA. Influence of Rhizoctonia solani and Trichoderma spp. in 
growth of bean (Phaseolus vulgaris L.) and in the induction of plant defense-related genes. Front Plant Sci. 2015;6:685.

29. Qin G, Tian S, Xu Y. Biocontrol of postharvest diseases on sweet cherries by four antagonistic yeasts in different storage conditions. Postharv Biol Technol. 2004;31:51-8.

30. Spadaro D, Ciavorella A, Dianpeng Z, Garibaldi A, Gullino ML. Effect of culture media and $\mathrm{pH}$ on the biomass production and biocontrol efficacy of a Metschnikowia pulcherrima strain to be used as a biofungicide for postharvest disease control. Can J Microbiol. 2010;56(2):128-37.

31. Dabrowska IV, Tkachenko KS, Podgorsky VS, Fomina MO. Anti-Staphylococci activity of yeast isolates affected by pH of experimental medium. Фaktopй ekcnerùmehtalshoï oprgahişmib; 2015. p. 179-82.

32. Tian $Y$, Li W, Jiang Z, Jing M, Shao Y. The preservation effect of Metschnikowia pulcherrima yeast on anthracnose of postharvest mango fruits and the possible mechanism. Food Sci Biotechnol. 2018;27(1):95-105.

33. Negri M, Martins M, Henriques M, Svidzinski TI, Azeredo J, Oliveira R. Examination of potential virulence factors of Candida tropicalis clinical isolates from hospitalized patients. Mycopathologia. 2010;169(3):175-82.

34. Manso T, Nunes C. Metschnikowia andauensis as a new biocontrol agent of fruit postharvest diseases. Postharvest Biol Technol. 2011;61(1):64-71.

35. Cecarini V, Cuccioloni M, Bonfili L, Ricciutelli M, Valzano M, Cappelli A, Amantini C, Favia G, Eleuteri AM, Angeletti M, Ricci I. Identification of a Killer Toxin from Wickerhamomyces anomalus with $\beta$-Glucanase Activity. Toxins. 2019;11:568-79.

36. Galán-Ladero MA, Blanco MT, Sacristán B, Fernández-Calderón MC, PérezGiraldo C, Gómez-García AC. Enzymatic activities of Candida tropicalis isolated from hospitalized patients. Med Mycol. 2010;48:207-10.

37. Bajaj BK, Raina S, Singh S. Killer toxin from a novel killer yeast Pichia kudriavzevii RY55 with idiosyncratic antibacterial activity. J of Basic Microbiol. 2013;53(8):645-56.

38. Sipiczki M. Overwintering of Vineyard Yeasts: Survival of Interacting Yeast Communities in Grapes Mummified on Vines. Front Microbiol. 2016;7:212.

39. O'Donell K. Fusarium and its near relatives. In: Reynolds DR, Taylor JW, editors. The Fungal Holomorph: Mitotic, Meiotic and Pleomorphic Speciation in Fungal Systematics. Wallingford: CAB International; 1993. p. $225-33$

\section{Publisher's Note}

Springer Nature remains neutral with regard to jurisdictional claims in published maps and institutional affiliations.

Ready to submit your research? Choose BMC and benefit from:

- fast, convenient online submission

- thorough peer review by experienced researchers in your field

- rapid publication on acceptance

- support for research data, including large and complex data types

- gold Open Access which fosters wider collaboration and increased citations

- maximum visibility for your research: over $100 \mathrm{M}$ website views per year

At $\mathrm{BMC}$, research is always in progress.

Learn more biomedcentral.com/submissions 